ISSN 0103-9954

\title{
METODOLOGIA PARA UTILIZAÇÃO DE CÂMARAS DE VÍDEO EM MAPEAMENTO FLORESTAL
}

\section{METHODOLOGY FOR USING VIDEO CAMERAS IN FOREST MAPPING}

\author{
Luciano Farinha Watzlawick $^{1}$ Pedro Roberto de Azambuja Madruga ${ }^{2}$ Rudiney Soares Pereira ${ }^{2}$
}

\section{RESUMO}

O presente trabalho apresenta o desenvolvimento metodológico de um sistema imageador, utilizando câmaras de vídeo convencionais e filtros espectrais (verde, vermelho e infravermelho próximo) como sensor não-convencional. Esse sensor possui como finalidade realizar mapeamento de áreas florestais. Para tal finalidade, foi realizado um estudo do espectro de cada filtro utilizado bem como o comportamento por ele apresentado nos diversos tipos de alvos. Como resultados, salienta-se a importância da obtenção das imagens quase que em tempo real, custos operacionais baixos, praticidade e operacionalidade do sistema bem como a agilidade de obtenção das imagens, e como desvantagem apresenta o comportamento espectral dos filtros utilizados se sobreporem e a baixa resolução espacial das câmaras VHS, aspectos esses que podem ser solucionados utilizando-se outros tipos de filtros nos mais diversos comprimentos de onda, e a utilização de câmaras S-VHS.

Palavras-chave: Mapeamento, videografia, sensoriamento remoto.

\begin{abstract}
The scope of this paper is the methodological development of an imaging system, which uses conventional video cameras and spectral filters (green, red, and near infrared) as non- conventional sensor. The sensor has the purpose of forest mapping. For that purpose, a spectral study of each filter was carried out as well as a study of filters' behavior in different types of targets. As a result, it is highlight the importance of obtaining images in almost real time, low operational costs, practicality and operationality of the system, as well as the agility to obtain images.As disadvantages, the system shows the overlaping of the filters' spectral behavior and the low spatial resolution of VHS cameras. Both of these factors can be solved by using other types of filters with different wavelengths and by using S-VHS cameras.
\end{abstract}

Key words: Mapping, videography, remote sensing.

\section{INTRODUÇÃO}

A realização de mapeamentos utilizando técnicas de sensoriamento remoto em áreas florestais, começou no Brasil com a utilização de fotografias aéreas de áreas florestais de difícil

1. Engenheiro Florestal, MSc., Doutorando em Ciências Florestais, Centro de Ciências Florestais e da Madeira, Av. Lothario Meissnner, 3400, Bairro Jardim Botânico, Universidade Federal do Paraná, CEP 80210-170, Curitiba (PR). luciano-farinha@uol.com.br

2. Engenheiro Florestal, Dr., Professor do Departamento de Engenharia Rural, Centro de Ciências Rurais, Universidade Federal de Santa Maria, CEP 97105-900, Santa Maria (RS). rudiney@ccr.ufsm.br 
acesso, primeiramente utilizando-se da fotointerpretação e da fotogrametria, tornando-se uma ferramenta imprencidível para a ciência florestal. Considerando que o desenvolvimento tecnológico dos sensores orbitais que imageiam atualmente a terra possuem uma resolução espacial e temporal que não suprem algumas necessidades da área florestal, como por exemplo o mapeamento de áreas pequenas, ou em áreas de regiões com grande período de cobertura de nuvens e nevoeiros, faz-se necessário desenvolver metodologias visando suprir a essas necessidades.

Pode-se exemplificar alguns potenciais da utilização das técnicas de sensoriamento remoto para mapeamento florestal, tais como: manejo florestal na determinação da área real ocupada pelas diferentes espécies no povoamento ou talhão, segundo classes de idade; tipo e grau de acessibilidade dos povoamentos; condição quanto à homogeneidade, densidade; distribuição espacial das classes de altura, diâmetro, volume; quais sítios apresentam melhor crescimento; proteção florestal na detecção e avaliação de problemas florestais, causados por insetos, causas patológicas, emissões de poluentes por indústrias, incêndios, inundações, tempestades...; no inventário florestal com a produção de mapas, estratificação florestal, lançamento de amostras a serem levantadas no campo ou mesmo para fins de elaboração de tabelas de volume, inventários florestais em múltiplos estágios; mapeamento e avaliação periódica de uma mesma área, em intervalos de tempo regulares, com finalidade de se estudar e controlar a dinâmica das mudanças; manejo de bacias hidrográficas nos estudos de vegetação, uso do solo, drenagem, classes de declividade ...

No Brasil, uma área pouco estudada e explorada, a recreação florestal, normalmente para a seleção de novas áreas requer a avaliação de vários locais alternativos bem como a procura de outros locais que apresentem potencial para serem adquiridos ou transformados em áreas de lazer, a utilização destas técnicas pode propiciar um inventário mais rápido, econômico e preciso, além de servirem como um documento histórico da área, pode ainda detectar problemas relacionados a caminhos ilegais dentro de grande áreas, mudanças no uso do solo, compactação do solo em algumas áreas "camping e pic-nic", inventários de rios e lagos, planejamento na construção de estradas, delimitação de áreas de interesses especiais, demarcação de territórios de fauna, entre outros...

As técnicas de sensoriamento remoto contribuem para a realização dos trabalhos de campo de coleta de dados, os quais são demorados e onerosos, dificultando, muitas vezes, avaliações periódicas dos recursos naturais. A utilização das imagens geradas por câmaras de vídeo acopladas com filtros espectrais vem a contribuir para o sensoriamento remoto, sendo uma maneira alternativa para a captura de imagens para realização de trabalhos de mapeamento. Nesse sentido, o presente trabalho tem como objetivo principal apresentar uma metodologia visando o mapeamento de área com cobertura florestal, utilizando câmara de vídeo VHS $(8 \mathrm{~mm})$, equipada com filtros na região do espectro eletromagnético no verde, vermelho e infravermelho próximo, possibilitando a aquisição de imagens multiespectrais.

\section{REVISÃO BIBLIOGRÁFICA}

As técnicas de sensoriamento remoto encontram sua maior aplicação no setor florestal, 
sendo muito utilizadas em trabalhos de inventário florestal para fins de elaboração de mapas, estratificação por classes de idade ou densidade, utilizando-se também para planejamentos de unidades amostrais a serem levantadas a campo, ou para fins de elaboração de tabelas aéreas de volume (CARNEIRO, 1981). Para exemplificar, cita-se o trabalho realizado por HERNANDEZ FILHO et al. (1993), na Floresta Nacional de Tapajós, realizando inventário florestal em múltiplos estágios, utilizando simultaneamente imagens de satélite, fotografias aéreas e dados de campo, permitindo uma estratificação e estimativa de área em hectares dos tipos florestais bem como o cálculo do volume médio e total.

A utilização de imagens do LANDSAT-TM, conjuntamente com a utilização de técnicas de geoprocessamento para o monitoramento da dinâmica do uso agrícola do solo e vegetação natural em microbacias, segundo VALÉRIO FILHO et al. (1997), apresentam um grande potencial, mesmo não sendo possível um maior detalhamento das classes de uso e cobertura vegetal das terras, em face das limitações dos produtos de sensoriamento remoto ao nível orbital. Salientam que as técnicas de sensoriamento remoto são ferramentas úteis para o monitoramento e a adequação de uso das terras em microbacias hidrográficas, pelo fato de propiciarem maior frequiência na atualização de dados, agilidade no processamento e ser economicamente viável.

A utilização de imagens de vídeo, ou propriamente dito a videografia é um sistema sensor não-convencional, aerotransportado, com finalidade de aquisição e interpretação de imagens utilizando câmaras de vídeo. (WATZLAWICK, 2000)

Conforme relata MYHRE (1993), a videografia apresenta muitas vantagens ao comparar-se com os métodos tradicionais de levantamento e monitoramento de infestação de pragas. Possui custos mais baixos que os métodos tradicionais de levantamento de campo, alta precisão, sendo mais rápida que métodos de fotografias aéreas tradicionais.

Além dos já citados, possui a vantagem do operador poder ver a imagem em um monitor simultaneamente com a aquisição, fazendo com que o processo de aquisição seja menos sujeito a erros que o da fotografia. Porém, salienta que imagens de vídeo apresentam a desvantagem de não possuírem boa qualidade quando comparadas com fotografias aéreas. O autor afirma que essa ferramenta permite ter estimativas da localização e da intensidade do dano da praga, bem como acompanhar as fases em desenvolvimento e monitorar as mudanças, sendo que tais áreas podem ser voadas como parte de um plano de monitoramento sistemático contínuo.

ROMNEY (1993) cita como vantagens que, na utilização de imagens de vídeo, é possível interpretar em tempo real, não necessitar processamento de filme, compatibilidade com ambientes de SIG, alta resolução e seus dados possuírem capacidade para processamento de imagens. Recomenda não utilizar para áreas extensas, por causa do intenso processo que envolve para criar os mosaicos automatizados, e para áreas extensas deveriam ser trabalhadas com imagens de satélite, sendo as imagem de vídeo excelente para prover inventários em áreas específicas. Poderiam ser utilizadas para estudar a variabilidade dentro de uma pequena área em consequência da alta resolução e auxiliar como áreas de treinamento para o desenvolvimento de classificação supervisionada para estudo em áreas maiores, com base em imagens de satélite.

As imagens de vídeo multiespectrais possuem aplicações em monitoramento de recursos 
naturais nas mais variadas áreas, estudos de comunidades vegetais ribeirinhas, avaliações rápidas de incêndios, aplicações para verificar o índice de pastagem (forragem), avaliações de mudanças de vegetação de áreas de inundação para avaliar a destruição, movimentos de água e solo, avaliações de locais de poluição, avaliações anuais das mudanças de infestação de ervas daninhas e insetos, monitoramento de vegetação, avaliação sucessional de medidas de saúde de ecossistemas em comunidades bem como outras aplicações e usos mais comuns dos dados para monitoramento dos recursos naturais (TUELLER, 1993).

Imagens de vídeo possuem aplicação na avaliação de queimadas, administração de recursos, estudos de habitats de vegetação, avaliação de danos de tempestade, traçados de cursos d'água, manejo florestal, inspecionar e monitorar a vida selvagem e possuem uma grande aplicação como apoio na verificação de imagens de satélite e levantamentos de amostras de treinamento (MYHRE, 1993).

Para inventariar os danos causados nas florestas pelo furacão Andrew (1992 - EUA), JACOBS \& EGGEN-MCINTOSH (1993) utilizaram câmara de vídeo S-VHS equipada com lente de $55 \mathrm{~mm}$. O vôo foi realizado a uma altitude de 600 metros, gerando imagens com uma resolução de 0,15 metros. A avaliação foi realizada por meio da interpretação visual utilizando dois tipos de dados: volume da copa e a forma, indicando árvores mortas, árvores prováveis de morrer e danos em árvores vivas. Concluíram que a videografia aerotransportada permitiram uma rápida avaliação dos danos, reduzindo a necessidade de levantamentos no campo da área afetada.

Para a realização de trabalhos de mapeamento florestal Evans \& Beltz (1992), apud DISPERATI \& DRAGO (1996) utilizaram imagens de vídeo como suporte para o inventário florestal, mostrando que estas foram utilizadas para diferenciação dos tipos florestais e para a determinação de densidade de copa das árvores.

Por outro lado, Fryar \& Clerke (1988), apud DISPERATI \& DRAGO (1996), avaliaram a utilização de fotografias aéreas $35 \mathrm{~mm}$ e de imagens aéreas multiespectrais de vídeo, para estimar a densidade de folhas em povoamento de Pinus taeda Engel e Pinus elliottii Engel de uma floresta dos Estados Unidos. Os resultados indicaram que a percentagem de erro com as imagens de vídeo se limitou a 12\% em 5 dos 19 talhões analisados; se comparados com dados terrestres, essa percentagem foi exatamente o dobro do erro proveniente das fotografias aéreas, em 10 dos 19 talhões.

Myhre (1987), apud DISPERATI \& DRAGO (1996), realizou um estudo comparativo de dados provenientes de mapeamentos aéreos (interpretação de fotografias), e de imagens de vídeo infravermelho em áreas atacadas por besouros-de-casca e por desfolhadores. Os resultados demonstraram que o grau de detalhamento no mapeamento dos danos de desfolhamento, obtido por meio da utilização de imagens de vídeo, foi superior ao resultado obtido mediante o mapeamento aéreo expedito, também foi observada uma melhor exatidão dos polígonos de danos nos mapas básicos.

Segundo MAUSEL et al. (1992), o método de videografia é uma nova maneira de obter produtos para o sensoriamento remoto, possuindo apenas problemas com sua baixa resolução e problemas com a calibração da câmara os quais limitam seu uso.

Ciência Florestal, v. 11, n. 2, 2001 
Conforme afirma DISPERATI \& DRAGO (1996), as imagens de vídeo têm sido uma ferramenta auxiliar nos trabalhos florestais, não sendo estas consideradas substitutivas das fotografias aéreas, mas complementares. Afirmam também haver uma evolução tecnológica das câmaras de vídeo e sistemas multiespectrais, sendo perfeitamente adaptável às condições brasileiras, com aplicações consideráveis na Engenharia Florestal.

\section{MATERIAL E MÉTODOS}

\section{Caracterização geral da área}

A área de estudo localiza-se no morro do Cerrito, município de Santa Maria, centro geográfico do estado do Rio Grande do Sul, a 2941'25" de latitude sul e 53\%48'42" de longitude oeste, com uma altitude aproximada de 138 metros.

Os solos são moderadamente drenados, com coloração bruno-avermelhada escura, textura argilosa e desenvolvem-se com base em rochas basálticas. A maior parte dos solos da região pertencem à Unidade de Mapeamento Ciríaco, não se constituem numa unidade simples, estando sempre associados aos solos Charrua, formando assim a Associação Ciríaco-Charrua, conforme nos relata LEMOS et al. (1973).

Pela classificação climática de Köppen, o clima é do tipo $C f a$, caracterizando-se como clima subtropical, apresentando os verões quentes e os invernos frios.

A vegetação do Morro do Cerrito pertence à Floresta Estacional Decidual (IBGE, 1992), destacando-se por ser uma área razoavelmente conservada, servindo como testemunha, a qual possui características peculiares.

A Floresta Estacional Decidual (Floresta Tropical Caducifólia) é caracterizada por apresentar duas estações climáticas bem-demarcadas, sendo uma chuvosa seguida de um longo período biológicamente seco. Na vegetação arbórea o estrato dominante e predominantemente caducifólio, com mais de 50\% dos indivíduos despidos de folhagem no período desfavorável. LONGHI (1993), ao realizar levantamento de fitossociologia na área de estudo, encontrou 31 famílias botânicas, 55 gêneros e 65 espécies, sendo que as famílias mais representadas foram: Leguminosae, Myrtaceae, Meliaceae, Euphorbiaceae, Lauraceae, Moraceae, Boraginaceae, Macoutiaceae e Rutaceae.

\section{Materiais}

Os materiais utilizados foram divididos em: materiais de apoio (câmara fotográfica, GPS de navegação Garmim XL 45 II, esteroscópio de bolso ZEISS, poliester, canetas, lápis, borracha... ); produtos cartográficos (carta DSG na escala 1:25.000 - Folha (SH.22-V-C-IV/1 MI - 2965/1 Santa Maria - SE); fotográficos (fotografias aéreas de médio formato coloridas na escala aproximada de 1:3.000) e imagens de vídeo multiespctrais; equipamentos de coleta de dados (GPS com precisão topográfica (Spectrum Packer da SOKIA), Espectrofotômetro Ultravioleta - Visível, Perkin-Elmer modelo 124, acoplado ao registrador PE 056, câmara de vídeo SONY CAMCORDER Handycam (8 
$\mathrm{mm}$ ), filtros espectrais: verde - 52mm KAISER, vermelho - $52 \mathrm{~mm}$ KAISER, infravermelho próximo - 52 mm HOYA).

\section{Métodos}

\section{Determinação do espectro dos filtros}

$\mathrm{Na}$ determinação dos espectros dos filtros, foi utilizado o Espectrofotômetro UltravioletaVisível, Perkin-Elmer modelo 124, acoplado ao registrador PE 056. O equipamento foi previamente calibrado com soluções-padrão de Dicromato de Potássio e Permanganato de Potássio. Após, procedeu-se à varredura do espectro entre $0,35 \mu \mathrm{m}$ a $0,85 \mu \mathrm{m}$, verificando a faixa de comprimentos de onda transmitidos pelos filtros verde, vermelho e infravermelho. Juntamente com o processo de varredura dos filtros, ocorreu o registro do espectro em papel.

\section{Planejamento do vôo e aquisição das imagens digitais}

O sistema para a aquisição de imagens digitais multiespectrais foi montado utilizando-se uma câmara de vídeo SONY CAMCORDER Handycam $(8 \mathrm{~mm})$, equipada com os filtros verde $(0,55$ $\mu \mathrm{m})$, vermelho $(0,65 \mu \mathrm{m})$ e infravermelho próximo $(0,72 \mu \mathrm{m})$; montada longitudinalmente sobre um suporte metálico e fixado no assoalho da aeronave (utilizou-se uma aeronave Cessna 172) para a tomada das imagens.

Com o sistema imageador desenvolvido, realizou-se sobrevôo na área teste conforme plano de vôo apoiado na carta topográfica elaborada pela DSG, folha (SH.22-V-C-IV/1 MI - 2965/1 Santa Maria - SE, escala 1:25.000), obedecendo os critérios básicos, como: velocidade da aeronave $(110 \mathrm{Km} / \mathrm{h})$, distância focal da câmara, escala da imagem gerada (1:11.400), altura do vôo acima do plano de referência, tamanho do CCD (retangular com $27 \mathrm{~mm} \mathrm{X} 21 \mathrm{~mm}$, (340 pixeis X 24 pixeis)) da câmara e distância entre as linhas de vôo, conforme se pode visualizar na Figura 1, gerando imagens com resolução de 1,0 m. Salienta-se que o recobrimento na linha de vôo (longitudinal) não é necessário por causa das câmaras de vídeo estarem continuamente coletando informações (30 quadros por segundo), gerando múltiplas imagens de um mesmo alvo, sendo o recobrimento lateral de $40 \%$.

\section{Conversão de dados e montagem do mosaico}

Considerando que a câmara de vídeo utilizada armazena os dados continuamente, na forma analógica e necessita ser convertida para o formato digital (raster), é necessário selecionar e congelar as imagens. Para essa finalidade foi utilizada a placa de Vídeo Blaster RT 300, e o software ADOBE PREMIERE LE 1.1. As imagens congeladas possuem o formato AVI, são exportadas para o formato BMP, utilizando o software PHOTOSTYLER, convertidas em tons de cinza e salvas no formato TIF. 
Valendo-se das diversas imagens selecionadas, realizou-se a montagem do mosaico semicontrolado para cada imagem correspondente a um filtro, utilizando o software ADOBE PHOTOSHOP. O processo é feito manualmente, selecionando duas imagens e recortando o centro destas, com a finalidade de diminuir as distorções geométricas. Realizou-se a identificação de pixels de controle comuns que sobreponham as duas imagens subseqüentes ao longo da linha de vôo, e entre as linhas de vôo. Enfatiza-se que o único processo no qual as imagens tiveram interferência foi a escala, não havendo qualquer interferência na tonalidade, brilho e contraste, permanecendo a imagem com suas características radiométricas próprias.

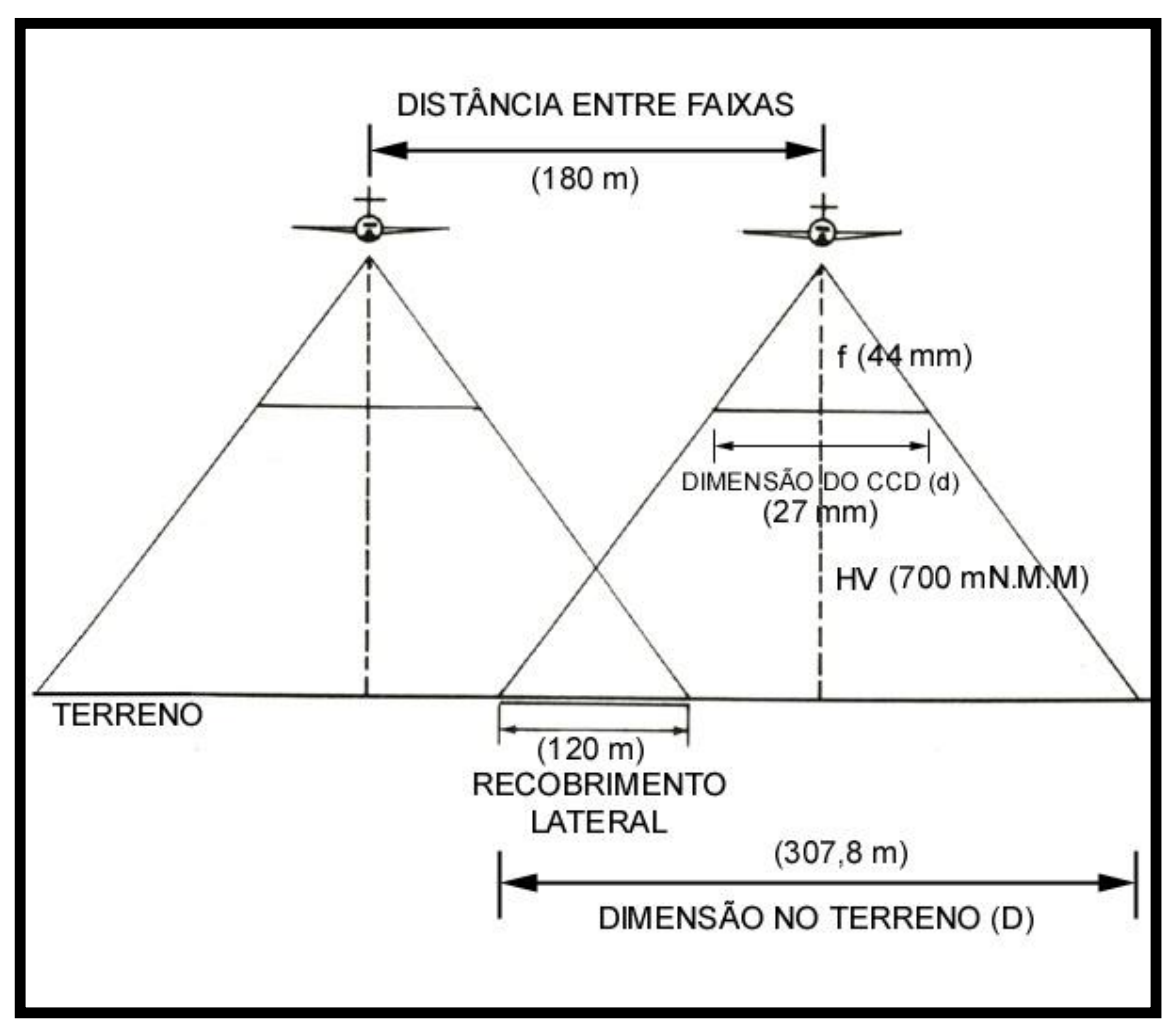

FIGURA 1: Relação entre duas linhas de vôo com critério básicos.

\section{Correção geométrica e registro das imagens}

Utilizou-se GPS (Global Positioning Sistem) com precisão topográfica (Spectrum Packer da SOKIA), para a coleta dos pontos de controle no campo, os quais foram definidos e distribuídos homogeneamente por toda a imagem.

Antes de realizar a correção geométrica, utilizou-se o módulo import do software IDRISI for Windows (versão 2.01), realizando-se a importação das três imagens (verde, vermelho e infravermelho) formato TIF para o formato IMG. As atividades de correção geométrica tornam-se necessárias por causa da instabilidade da aeronave que produziu distorções nas imagens. Contribuindo para estas distorções tem-se a variação da altitude, velocidade da aeronave, instabilidade devido a ventos, e distorções relacionadas ao próprio operador da câmara. 
Para a correção geométrica bem como para o registro, foi utilizado o método do vizinho mais próximo, com a função de mapeamento linear. Foi utilizado por ser o método que melhor preserva o valor original do $\mathrm{DN}$, em consequência deste não envolver médias. A correção geométrica utilizando-se 8 pontos de controle, sendo realizada no mosaico produzido com base na imagem gerada pelo filtro infravermelho, apresentando um RMS (erro médio quadrático) de 1,423554 m. Já o registro foi realizado nas três imagens (verde, vermelho e infravermelho), utilizando-se 24 pontos de controle da imagem infravermelho anteriormente corrigida geometricamente (coordenadas no Sistema UTM (m)). O processo de registro é realizado por ser necessária a justaposição das imagens. Sendo assim, os três imagens possuem o mesmo sistema referencial de coordenadas. O RMS obtido após o processo de registro da imagem para o filtro verde foi de 1,138018 m. Para o vermelho foi $1,097896 \mathrm{~m}$ e para o infravermelho próximo de 1,005413 $\mathrm{m}$. Esse valor é considerado baixo, por ser bem próximo a um pixel.

\section{Comportamento espectral dos alvos (temas de uso da terra)}

Para verificar o comportamento espectral dos alvos nos filtros usados, utilizou-se o módulo histo do software IDRISI for Windows (versão 2.01), em que foram selecionadas áreas de treinamento das diversas classes de uso da terra: floresta nativa, grama, arbusto-grama, capoeira, solo exposto, afloramento, área de lavoura, calçamento e edificações. Para auxiliar a identificação e reconhecimento, utilizou-se fotografias aéreas coloridas de médio formato, e trabalho de campo para verificação. Com o histograma de cada classe de uso da terra em cada uma das três bandas utilizadas (verde, vermelho e infravermelho), obteve-se valores de brilho mínimos e máximos - DN (número digital). Para melhor visualização dos gráficos utilizou-se o software EXCEL for Windows 98.

\section{RESULTADOS E DISCUSSÃO}

Conforme pode-se observar na Figura 2, o comportamento espectral dos filtros utilizadados são seletivos sobre os comprimentos de onda em que se quer que a energia refletida por um alvo chegue ao sensor. Justifica-se a importância dessa seletividade, porque, muitas vezes, dois alvos (temas de uso da terra) podem apresentar a mesma cor, quando vistos na porção visível do espectro, mas podem ter características de reflexão diferentes na região do infravermelho próximo. A diferenciação entre os dois e a utilização de filtros é importante por causa da utilização das imagens para processos de classificação automática de imagens. Os filtros espectrais utilizados são de absorção, constituídos de vidro, sendo estes limitados em relação à seletividade do comprimento de onda.

As Figuras 3, 4 e 5 bem como a Tabela 1 apresentam as respostas espectrais das classes de uso da terra bem como valores de brilho - DN (número digital), em razão da classe de uso da terra, da composição e arranjo dos mesmos em cada região do espectro eletromagnético que está sendo trabalhada (verde, vermelho e infravermelho próximo). 


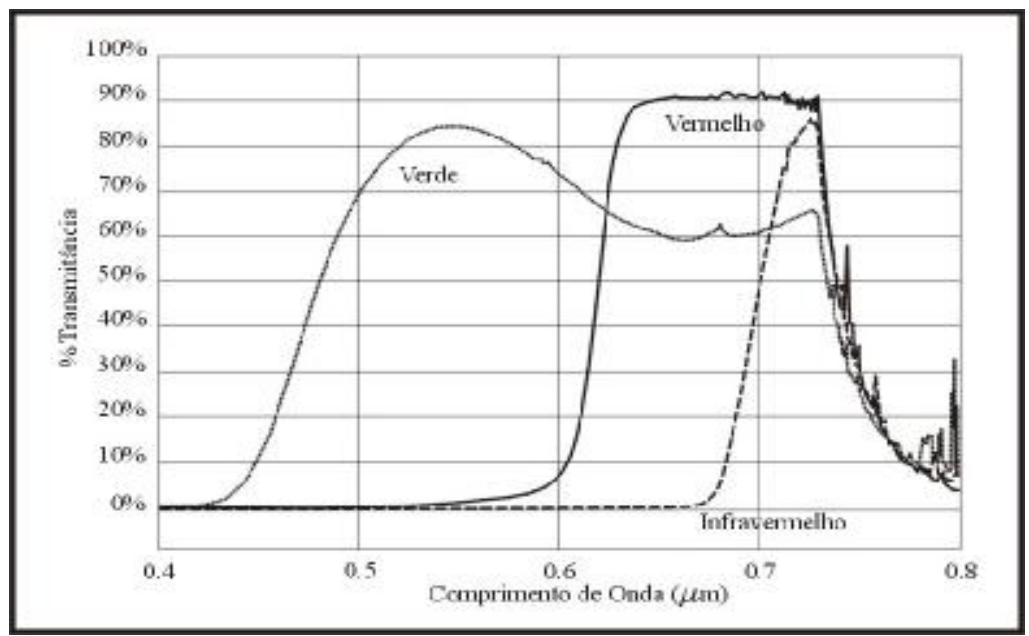

FIGURA 2: Espectro dos filtros verde, vermelho e infravermelho.

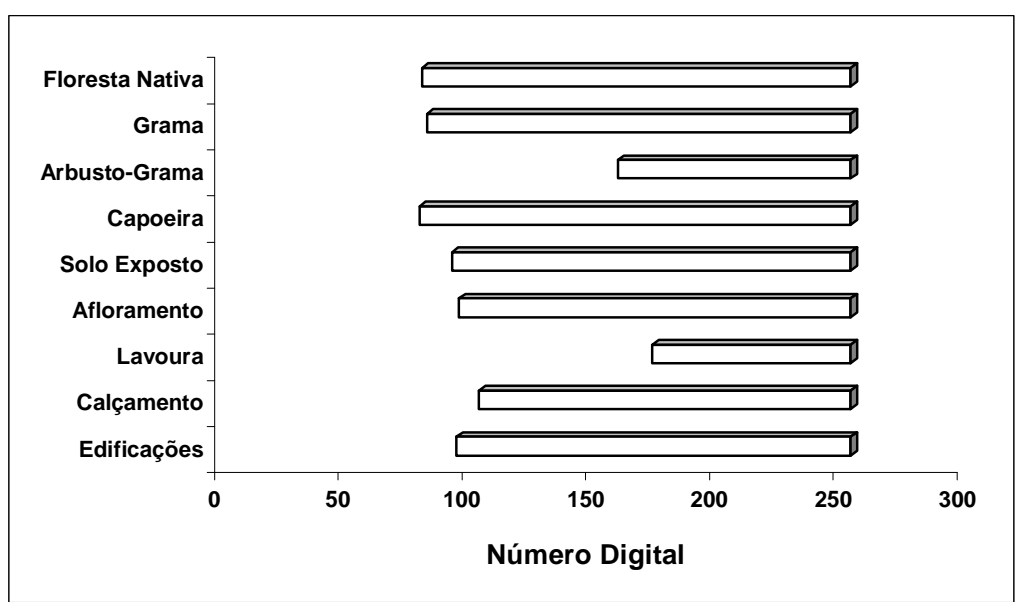

FIGURA 3: Valores de brilho das classes de uso da terra na banda verde.

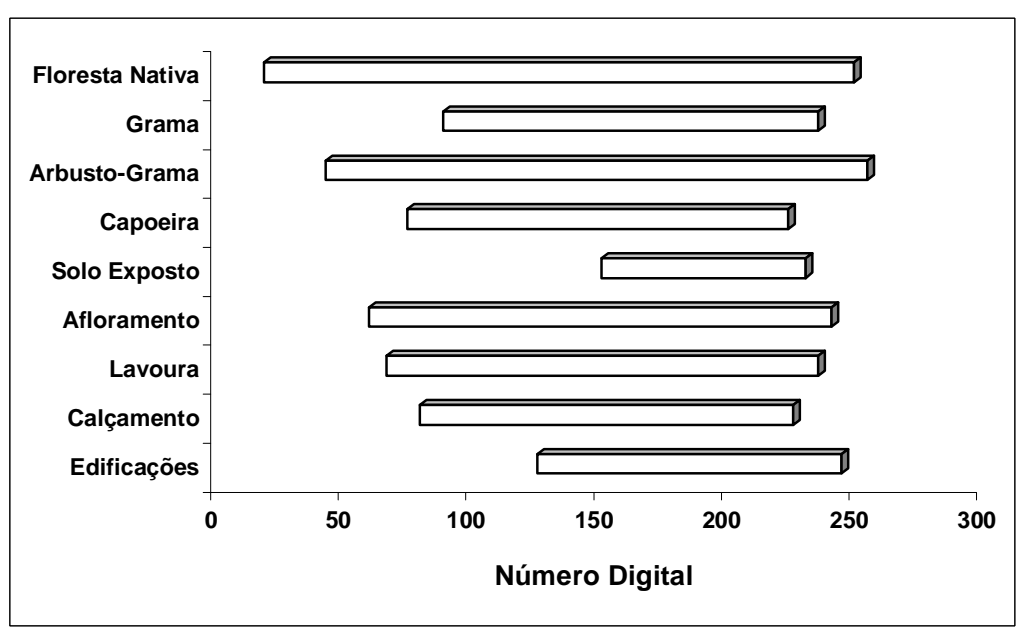

FIGURA 4: Valores de brilho das classes de uso da terra na banda vermelha. 


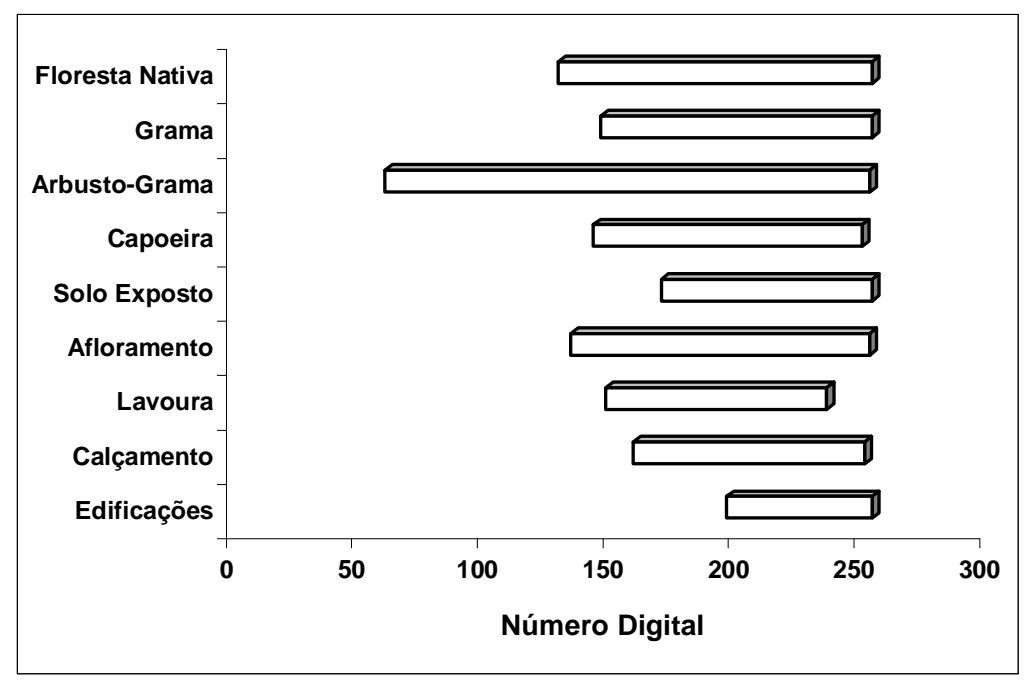

FIGURA 5: Valores de brilho das classes de uso da terra na banda infravermelho próximo.

TABELA 1: Valores mínimos e máximos de DN (digital number) para as classes de uso terra nas regiões do espectro eletromagnético trabalhadas.

\begin{tabular}{|c|c|c|c|c|c|c|}
\hline \multirow{3}{*}{$\begin{array}{l}\text { Classes } \\
\text { de uso } \\
\text { da terra }\end{array}$} & \multicolumn{6}{|c|}{ Bandas } \\
\hline & \multicolumn{2}{|c|}{ Verde } & \multicolumn{2}{|c|}{ Vermelho } & \multicolumn{2}{|c|}{ Infravermelho } \\
\hline & Mínimo & Máximo & Mínimo & Máximo & Mínimo & Máximo \\
\hline Floresta Nativa & 82 & 255 & 19 & 250 & 130 & 255 \\
\hline Grama & 84 & 255 & 89 & 236 & 147 & 255 \\
\hline Arbusto-Grama & 161 & 255 & 43 & 255 & 61 & 254 \\
\hline Capoeira & 81 & 255 & 75 & 224 & 144 & 251 \\
\hline Solo Exposto & 94 & 255 & 151 & 231 & 171 & 255 \\
\hline Afloramento & 97 & 255 & 60 & 241 & 135 & 254 \\
\hline Lavoura & 175 & 255 & 67 & 236 & 149 & 237 \\
\hline Calçamento & 105 & 255 & 80 & 226 & 160 & 252 \\
\hline Edificações & 96 & 255 & 126 & 245 & 197 & 255 \\
\hline
\end{tabular}

Pode-se observar que a Floresta Nativa, em razão de possuir uma composição e arranjo das copas heterogêneas, possui menores valores de brilho na região do visível, conforme se observa a Figura 3, a banda do verde $(\mathrm{DN}=82)$ e Figura 4, banda do vermelho $(\mathrm{DN}=19)$, porém apresenta maior amplitude, em razão da grande variedade, e tipo de pigmentos. A banda do infravermelho (Figura 5) apresenta alto valor de brilho $(\mathrm{DN}=130)$, por existir pouca absorção de radiação nesta região, conseqüentemente temos uma região de alta reflectância $(\mathrm{DN}=255)$.

A Grama, nas bandas do verde (Figura 3) e vermelho (Figura 4), apresenta comportamento semelhante, em razão de possuir uma estrutura e composição homogênea, porém apresenta um comportamento diferenciado na banda do infravermelho (Figura 5), pelo baixo teor de umidade, apresenta maiores valores mínimos de brilho $(\mathrm{DN}=147)$, em razão de estar localizada nos locais mais elevados. 
O tema Arbusto/Grama, foi agrupado em razão destes tipos de vegetação encontrarem-se juntas na área de estudo. Observa-se que em razão de possuir uma certa homogeneidade na estrutura, apresenta uma pequena amplitude de variação na banda do verde (Figura 3), já nas bandas do vermelho (Figura 4) e infravermelho próximo (Figura 5) não apresentam variação entre si, porém na região do infravermelho apresenta um alto teor de umidade, justifica-se tal afirmação pela a vegetação ser irrigada.

$\mathrm{Na}$ Capoeira, composta por uma vegetação arbustiva de vassourão e vassoura vermelha, observa-se que o comportamento na banda do verde (Figura 3) e vermelho (Figura 4), apresentam semelhante amplitude, por causa da estrutura das plantas (parênquima), tendência comprovada em razão da banda do infravermelho próximo (Figura 5) apresentar menores valores de amplitude e maiores valores mínimos de brilho $(\mathrm{DN}=144)$, estando associado à estrutura de disposição das plantas e ao comportamento espectral da vegetação.

O Solo Exposto, tem seu comportamento espectral determinado em razão da variabilidade da composição química, matéria orgânica, granulometria e os teores de umidade. Conforme pode ser observado na Figura 3, a maior amplitude de variação dos valores de brilho ocorrem na banda verde, porém na banda do vermelho (Figura 4) apresenta menor amplitude e valor digital mínimo maior ( $\mathrm{DN}=151)$ que na banda do verde $(\mathrm{DN}=94)$, em consequência da composição do material de origem. O solo apresenta-se seco, em razão de estar refletindo bastante na banda do infravermelho próximo (Figura 5), sendo possível fazer tal diferenciação das diferentes concentrações de teores de umidade apenas na banda do infravermelho.

A área com agricultura, denominada como Lavoura, possui o plantio da cultura do milho e da cana-de-açúcar. Ao observar-se o alto valor de brilho (DN = 175) na banda do verde (Figura 3), sendo responsável possivelmente por esses valores o tipo de preparo de solo e a rugosidade do terreno, a qual apresenta estrias, que estão expostas ao sol e apresentam uma grande freqüência de pixel respondendo pelo fator iluminação. $\mathrm{Na}$ banda do vermelho (Figura 4), apresenta maior amplitude, em razão da maior variabilidade da textura (superfície da lavoura). O comportamento espectral dos Afloramentos Rochosos é semelhante ao dos solos, as diferenças ocorrem em razão da presença de matéria orgânica, teores de umidade, que mascaram as bandas de absorção dos minerais componentes das rochas.

O Calçamento, conforme se pode observar nas Figuras 3 e 4, apresenta mesma amplitude, responsável pela correlação razoável em razão do material de origem utilizado na pavimentação possuir certa homogeneidade.

As Edificações apresentam, na banda do infravermelho próximo (Figura 5), a tendência de diminuir a amplitude em decorrência do tipo de material de origem, porém a resposta espectral apresenta os valores mais altos.

\section{CONCLUSÕES}

Com base na metodologia proposta e em razão dos resultados obtidos, pode-se concluir que 
a metodologia se prestou aos objetivos propostos.

Os resultados apresentados no comportamento espectral dos temas de uso da terra, os quais possuem uma certa sobreposição nas três bandas trabalhadas (verde, vermelho e infravermelho próximo), permitiram concluir-se e ressaltar-se que essa sobreposição dificulta no momento da utilização das imagens para realização de classificação automática de imagens.

Conclui-se também que a utilização de câmaras de vídeo como sensor não-convencional é viável, por apresentar baixo custo, em razão de necessitar apenas horas de vôo, suporte com câmaras de vídeo adaptados com filtros e operador treinado, bem como a aquisição e análise das imagens geradas em tempo real. Com a realização do presente trabalho, indica a possibilidade da utilização de videografia multiespectral para a produção de mapas temáticos de uso e cobertura da terra.

Para a realização de trabalhos futuros, recomenda-se utilizar filtros que possuam resolução espectral bem-diferenciada. Na realização do sobrevôo, utilizar na medida do possível o mesmo número de câmaras de vídeo que o número de filtros, evitando-se assim passagens múltiplas sobre a área bem como menores diferenças de distorções nas imagens ou distorções semelhantes.

\section{REFERÊNCIAS BIBLIOGRÁFICAS}

CARNEIRO, C. M. R. Importância das técnicas de sensoriamento remoto para a ciência florestal. Brasília: Ministério da Agricultura, IBDF, 1981. 21 p.

DISPERATI, A. A; DRAGO, D. Videografia aplicada à engenharia florestal. In: GIS BRASIL, 1996, Curitiba. Anais... Curitiba, 1996. p 252 - 258.

HERNANDEZ FILHO, P.; SHIMABUKURO, Y. E.; LEE, D. C. L. et al. Projeto de inventário florestal na floresta nacional do Tapajós: relatório final. São José dos Campos: INPE, 1993. 126 p.

JACOBS, D. M.; EGGEN-MCINTOSH, S. Forest resouse damage assessment of hurricane andrew in southern Louisiana usisng airborne videography. In: BIENNIAL WORKSHOP ON COLOR AERIAL PHOTOGRAPHY AND VIDEOGRAPHY FOR RESOUSE MONITORING, 14., 1993, Logan. Proceedings... Logan: American Society for Photogrammetry and Remote Sensing, 14 th., Logan, Utah, May 1993. p. 115 - 124.

IBGE. Manual técnico da vegetação brasileira. Rio de Janeiro, 1992. 92 p.

LEMOS, R. C.; AZOLIN, M. A. D.; ADRAÃO, P. V. R. et al.. Levantamento de reconhecimento dos solos do Estado do Rio Grande do Sul. Recife: Ministério da Agricultura - Departamento de Pesquisas Agropecuárias - Divisão de Pesquisas Pedológicas, 1973. 431 p. (Boletim Técnico, n. 30).

LONGHI, S. J. Aspéctos fitossociológicos comparativos da vegetação arbórea de quatro morros de Santa Maria - RS. Santa Maria: UFSM, 1993. Dissertação (Obtenção do Título de Professor Titular) Universidade Federal de Santa Maria, 1993.

MAUSEL. P. W.; EVERITT, J. H.; ESCOBAR, D. E. et al. Airbone videography: current status and future perspectives. Photogrammetric Engeineering \& Remote Sensing, v. 58, n. 8, p. 1189-1195, Aug. 1992.

MYHRE, R. J. A color airborne video system developed within the U.S. forest service. In: BIENNIAL

Ciência Florestal, v. 11, n. 2, 2001 
WORKSHOP ON COLOR AERIAL PHOTOGRAPHY AND VIDEOGRAPHY FOR RESOUSE MONITORING, 14 th., 1993, Logan, Utah. Proceedings... Logan, 1993. p. 9 - 18.

ROMNEY, J. A. Use of airborne videography as a tool for abandoned mines/hazardous materials site inventory. In: BIENNIAL WORKSHOP ON COLOR AERIAL PHOTOGRAPHY AND VIDEOGRAPHY FOR RESOUSE MONITORING, 14 th, Logan, Utah. Proceedings... Logan, 1993. p.68-81.

TUELLER, P. T. A. Low-cost multispectral airborne video image system for vegetation monitoring on range and forest lands. In: BIENNIAL WORKSHOP ON COLOR AERIAL PHOTOGRAPHY AND VIDEOGRAPHY FOR RESOUSE MONITORING, 14 th, Logan, Utah. Proceedings... Logan, 1993. p. $1-8$.

VALÉRIO FILHO, M.; DONZELI, P. L.; PINTO, S. A. F. et al. Monitoramento da dinâmica do uso agrícola e vegetação natural em microbacias hidrográficas através de técnicas de sensoriamento remoto e geoprocessamento. In: CONGRESSO BRASILEIRO DE CIÊNCIA DO SOLO, 26, 1997, Rio de Janeiro. Anais... CD-ROM.

WATZLAWICK, L. F. Avaliação de classificadores a partir de dados coletados através de videografia multiespectral. Porto Alegre: UFRGS: 2000, 138 p. Dissertação (Mestrado em Sensoriamento Remoto) Centro Estadual de Pesquisas em Sensoriamento Remoto e Meteorologia, Universidade Federal do Rio Grande do Sul, 2000. 